\title{
LONG MEMORY IN THE GREEK STOCK MARKET
}

\author{
John T. Barkoulas \\ Department of Economics \\ Boston College \\ Chestnut Hill, MA 02167 USA \\ Christopher F. Baum* \\ Department of Economics \\ Boston College \\ Chestnut Hill, MA 02167 USA \\ Nickolaos Travlos \\ Boston College, \\ University of Piraeus, \\ and Athens Laboratory of Business Administration
}

\begin{abstract}
We test for stochastic long memory in the Greek stock market, an emerging capital market. The fractional differencing parameter is estimated using the spectral regression method. Contrary to findings for major capital markets, significant and robust evidence of positive long-term persistence is found in the Greek stock market. As compared to benchmark linear models, the estimated fractional models provide improved out-of-sample forecasting accuracy for the Greek stock returns series over longer forecasting horizons.
\end{abstract}

Keywords: Emerging capital markets, forecasting, long memory, ARFIMA processes, spectral regression.

JEL Classification: G14, G15, C53

* Corresponding author, tel: 617-552-3673, fax: 617-552-2308, email: baum@bc.edu. 


\section{LONG MEMORY IN THE GREEK STOCK MARKET}

\section{Introduction}

The potential presence of stochastic long memory in financial asset returns has been an important subject of both theoretical and empirical research. If asset returns display long memory, or long-term dependence, they exhibit significant autocorrelation between observations widely separated in time. Since the series realizations are not independent over time, realizations from the remote past can help predict future returns, giving rise to the possibility of consistent speculative profits. The presence of long memory in asset returns contradicts the weak form of the market efficiency hypothesis, which states that, conditioning on historical returns, future asset returns are unpredictable. ${ }^{1}$

A number of studies have tested the long-memory hypothesis for stock market returns. Using the rescaled-range (R/S) method, Greene and Fielitz (1977) report evidence of persistence in daily U.S. stock returns series. A problem with the classical R/S method is that the distribution of its test

1 The existence of long memory in asset returns calls into question linear modeling and invites the development of nonlinear pricing models at the theoretical level to account for long-memory behavior. Mandelbrot (1971) observes that in the presence of long memory, the arrival of new market information cannot be fully arbitraged away and martingale models of asset prices cannot be obtained from arbitrage. In addition, pricing derivative securities with martingale methods may not be appropriate if the underlying continuous stochastic processes exhibit long memory. Statistical inferences concerning asset pricing models based on standard testing procedures may not be appropriate in the presence of long-memory series (Yajima (1985)). 
statistic is not well defined and is sensitive to short-term dependence and heterogeneities of the underlying data generating process. These dependencies bias the classical R/S test toward finding long memory too frequently. Lo (1991) developed a modified R/S method which addresses these drawbacks of the classical $R / S$ method. Using this variant of $R / S$ analysis, Lo (1991) finds no evidence to support the presence of long memory in U.S. stock returns. Using both the modified R/S method and the spectral regression method (described below), Cheung and Lai (1995) find no evidence of persistence in several international stock returns series. Crato (1994) reports similar evidence for the stock returns series of the G-7 countries using exact maximum likelihood estimation. The primary focus of these studies has been the stochastic long-memory behavior of stock returns in major capital markets.

In contrast, the question of long memory in smaller markets has received little attention. Outside the world's developed economies, there is a host of emerging capital markets (hereafter ECM) in developing economies that, in recent years, has attracted a great deal of attention from investors and investment funds seeking to further diversify their assets. Despite temporary setbacks, ECMs will continue to be important conduits of diversification and a complete characterization of the dynamic behavior of stock returns in ECMs is warranted. It must be noted that ECMs are very likely to exhibit characteristics different from those observed in developed capital markets. Biases due to market thinness and nonsynchronous trading should be expected to be more severe in the case of ECMs. Also, in contrast to developed capital markets which are highly efficient in terms of the speed of information reaching all traders, investors in emerging capital markets tend to react slowly and gradually to new information. In this paper, we look for 
evidence of long memory in one such emerging capital market: the Greek stock market.

The Greek stock market is represented by the Athens Stock Exchange (hereafter ASE), which had about 220 listings for common and preferred equities as of the end of 1990. Until the beginning of 1987, interest in the ASE was limited to Greek nationals. Then the government freed capital controls for securities investments which helped the market to take off due to the interest shown by the European Economic Community (EEC) and thirdcountry investors. This movement was further helped by the government stabilization program of 1985-1987 which stimulated corporate profits and created much optimism about their future growth. The market rallied during the first nine months of 1987 resulting in an increase of $1068.27 \%$ in the stock index prior to the October 1987 international stock market crisis. Despite sharp declines in the last three months of 1987, the stock index enjoyed its highest annual return of over $250 \%$ in that year. The market did not overcome the negative effect of the October stock market crisis and for the next year and a half foreign investors left the Greek market (the stock index decreased $18.04 \%$ in that period).

In mid-1989, due to the impressive positive developments that occurred in many EEC economies as well as the expectations that the Conservative party would return to power, foreign investors returned to Greece and a new rally began. In 1990, the return of a Conservative government to power and the expectation of a more liberalized economy (as evidenced by the government's intention to privatize many state enterprises) provided a boost to the market and brought stock prices and trade volume up to record levels. From July 1989 to the beginning of July 1990 the stock index recorded an increase of $613.20 \%$. The rally ended in July 1990 as the 
market reacted negatively to the Middle East crisis (the Iraqi invasion of Kuwait) and, later on, to the government's failed bid to host the 1996 Olympic Games. From July through December 1990 the stock index recorded a decrease of $41.68 \%$.

The Greek authorities are committed to modernizing and liberalizing the ASE in order to increase its efficiency and make it more accessible to international investors. The reforms that were introduced by the new stock exchange law (L. 1806/88) are expected to positively affect the market and lead to the expansion of its activities. The introduction of new financial instruments, like warrants, options, commercial paper, etc. is currently under way. There is no capital gains tax in Greece.

There has been limited research on the behavior of stocks traded on the ASE. Papaioannou $(1982,1984)$ reports price dependencies in stock returns for a period of at least six days. Panas (1990) provides evidence of weak-form efficiency for ten large Greek firms. Koutmos, Negakis, and Theodossiou (1993) find that an exponential generalized ARCH model is an adequate representation of volatility in weekly Greek stock returns. The intertemporal relation between the U.S. and Greek stock markets is analyzed in Theodossiou, Koutmos, and Negakis (1993). Barkoulas and Travlos (1996) test whether Greek stock returns are characterized by deterministic nonlinear structure (chaos).

In this paper, we test for the presence of fractional dynamics, or long memory, in the returns series for the Greek stock market. The fractional differencing parameter is estimated through application of the spectral regression method on weekly data for a carefully constructed stock index over a ten-year period. To address market efficiency issues, the forecasting performance of the estimated fractional models is compared to that of 
benchmark linear models on an out-of-sample basis. The obtained results strongly suggest that the stochastic long-memory behavior of the Greek stock market-an emerging capital market-markedly differs from that of major, well-developed stock markets. Long-memory forecasts of Greek stock returns dominate linear forecasts over longer forecasting horizons.

The plan of the paper is as follows. Section 2 presents the spectral regression method. In section 3 the data set is described and empirical estimates of the fractional differencing parameter are presented. A forecasting experiment is performed in section 4 . Concluding remarks are presented in section 5 .

\section{The Spectral Regression Method}

The model of an autoregressive fractionally integrated moving average process of order $(p, d, q)$, denoted by $\operatorname{ARFIMA}(p, d, q)$, with mean $\mu$, may be written using operator notation as

$$
\Phi(L)(1-L)^{d}\left(y_{t}-\mu\right)=\Theta(L) u_{t}, \quad u_{t} \sim \text { i.i.d. }\left(0, \sigma_{u}^{2}\right)
$$

where $L$ is the backward-shift operator, $\Phi(L)=1-\phi_{1} L-\ldots-\phi_{p} L^{p}, \Theta(L)=1+$ $\vartheta_{1} L+\ldots+\vartheta_{q} L^{q}$, and $(1-L)^{d}$ is the fractional differencing operator defined by

$$
(1-L)^{d}=\sum_{k=0}^{\infty} \frac{\Gamma(k-d) L^{k}}{\Gamma(-d) \Gamma(k+1)}
$$

with $\Gamma(\cdot)$ denoting the gamma function. The parameter $d$ is allowed to assume any real value. The arbitrary restriction of $d$ to integer values gives 
rise to the standard autoregressive integrated moving average (ARIMA) model. The stochastic process $y_{t}$ is both stationary and invertible if all roots of $\Phi(L)$ and $\Theta(L)$ lie outside the unit circle and $|d|<0.5$. The process is nonstationary for $d \geq 0.5$, as it possesses infinite variance, i.e. see Granger and Joyeux (1980). Assuming that $d \in(0,0.5)$ and $d \neq 0$, Hosking (1981) showed that the correlation function, $\rho(\cdot)$, of an ARFIMA process is proportional to $k^{2 d-1}$ as $k \rightarrow \infty$. Consequently, the autocorrelations of the ARFIMA process decay hyperbolically to zero as $k \rightarrow \infty$ which is contrary to the faster, geometric decay of a stationary ARMA process. For $d \in(0,0.5), \sum_{k=-n}^{n}|\rho(k)|$ diverges as $n \rightarrow \infty$, and the ARFIMA process is said to exhibit long memory, or longrange positive dependence. ${ }^{2}$ The process exhibits intermediate memory, or long-range negative dependence for $d \in(-0.5,0)$ and short memory for $d=0$, corresponding to a stationary and invertible ARMA model. For $d \in[0.5,1)$ the process is mean reverting, even though it is not covariance stationary, as there is no long run impact of an innovation to future values of the process.

Geweke and Porter-Hudak (1983) suggested a semi-parametric procedure to obtain an estimate of the fractional differencing parameter $d$ based on the slope of the spectral density function around the angular frequency $\xi=0$. More specifically, let $I(\xi)$ be the periodogram of $\mathbf{y}$ at frequency $\xi$ defined by

$$
I(\xi)=\frac{1}{2 \pi T}\left|\sum_{t=1}^{T} e^{i t \xi}\left(y_{t}-\bar{y}\right)\right|^{2}
$$

Then the spectral regression is defined by

2 Other authors refer to a process as a long memory process for all $d \neq 0$. 


$$
\ln \left\{I\left(\xi_{\lambda}\right)\right\}=\beta_{0}+\beta_{1} \ln \left\{4 \sin ^{2}\left(\frac{\xi_{\lambda}}{2}\right)\right\}+\eta_{\lambda}, \quad \lambda=1, \ldots, v
$$

where $\xi_{\lambda}=\frac{2 \pi \lambda}{T}(\lambda=0, \ldots, T-1)$ denotes the Fourier frequencies of the sample, $T$ is the number of observations, and $v=g(T)<<T$ is the number of Fourier frequencies included in the spectral regression.

$$
\text { Assuming that } \lim _{T \rightarrow \infty} g(T)=\infty, \lim _{T \rightarrow \infty}\{g(T) / T\}=0 \text {, and } \lim _{T \rightarrow \infty} \ln (T)^{2} / g(T)=0,
$$

the negative of the slope coefficient in (4) provides an estimate of $d$. Geweke and Porter-Hudak (1983) prove consistency and asymptotic normality for $d<0$, while Robinson (1990) proves consistency for $d \in(0,0.5)$. Hassler (1993) proves consistency and asymptotic normality in the case of Gaussian innovations in (1). The spectral regression estimator is not $T^{1 / 2}$ consistent as it converges at a slower rate. The theoretical variance of the error term in the spectral regression is known to be $\pi^{2} / 6$.

\section{Data and Empirical Estimates}

The data set consists of weekly stock returns based on the closing prices of a value-weighted index comprised of the thirty most heavily traded stocks (during the period 1988-1990) on the Athens Stock Exchange (ASE30) developed by Travlos (1992). The sample period spans $01 / 07 / 1981$ to $12 / 27 / 1990$ for a total of 521 weekly observations. The period $01 / 07 / 1981$ to $10 / 11 / 1989$ is used for in-sample estimation with the remaining observations used for out-of-sample forecasting. An important feature of this index is that prices of individual stocks have been adjusted to reflect any distribution of cash and/or securities, such as cash dividends, stock dividends, etc. as well as 
for any changes in the firm's capital accounts which cause artificial changes in the associated stock prices. This stock index is of much higher quality than the Athens Stock Exchange composite index, which includes all companies listed. The latter index is very prone to biases due to market thinness. Figure 1 illustrates the ASE30 returns series over the entire sample period.

The period under analysis is of major importance because the decade of the 1980s was associated with major changes in the political and economic environment in Greece. First, in the political arena the ruling Conservative Party was replaced in government by the Socialist Party which in turn gave way to another Conservative administration. Second, during this period Greece became a full member of the EEC and undertook many institutional changes in the money and capital markets. These changes affected the investment opportunities of investors and, consequently, securities' riskreturn characteristics.

Before we proceed with formal statistical analysis we provide some more evidence regarding the performance of the Greek stock market. 100 drachmas invested on December 31, 1980 in the portfolio of stocks contained in our stock index grows to 6,005 drachmas on December 31, 1990 resulting in an (geometric) average annual rate of return of $50.61 \%$. Investors of stocks were subjected to a large standard deviation $(88.75 \%)$ of the annual rate of return. For comparison purposes the associated geometric mean (standard deviation) for common stocks in the U.S. over the past decade were $13.93 \%$ (13.23\%). That is, over the period 1981-1990 the average annual rate of stock returns in the ASE was about four times larger than in the U.S. market, while the total risk was about seven times larger. Figure 2 presents the annual stock returns for each year in the sample period. The highest annual return was over 250\% in 1987 and the lowest return reached about -35\% in 1983. 
Table 1 reports the summary statistics for ASE30 weekly returns over the in-sample period $(01 / 07 / 1981-10 / 11 / 1989)$. The sample mean return is positive and statistically significant at the one per cent level. There are significant departures from normality as the series is positively skewed and leptokurtic. ${ }^{3}$

Table 2 presents the spectral regression estimates of the fractional differencing parameter $d$ for the ASE30 returns series over the in-sample period. A choice must be made with respect to the number of low-frequency periodogram ordinates used in the spectral regression. Improper inclusion of medium- or high-frequency periodogram ordinates will contaminate the estimate of $d$; at the same time too small a regression sample will lead to imprecise estimates. In light of the suggested choice by Geweke and PorterHudak (1983) based on forecasting and simulation experiments, we report fractional differencing estimates for $v=T^{0.50}, T^{0.525}, T^{0.55}, T^{0.575}$, and $T^{0.60}$ to evaluate the sensitivity of our results to the choice of the sample size of the spectral regression. To test the statistical significance of the $d$ estimates, twosided ( $d=0$ versus $d \neq 0$ ) as well as one-sided ( $d=0$ versus $d>0)$ tests are performed. To raise estimation efficiency, the known theoretical variance of the regression error $\pi^{2} / 6$ is imposed in the construction of the $t$-statistic for $d$.

As Table 2 reports, there is evidence that the ASE30 returns series exhibits fractional dynamics with long-memory features. The fractional differencing parameters are similar in value across the various sample sizes of

3 The ASE30 returns series exhibits linear dependence in the mean based on Q-statistics for serial correlation. It also exhibits significant time variation in the second moment based on Engle's (1982) Lagrange Multiplier test for autoregressive conditional heteroscedasticity $(\mathrm{ARCH})$. These results are not reported here but are available upon request from the authors. 
the spectral regression and range from 0.2 to 0.3 in value. The Greek stock returns series is not an $I(0)$ process, which would exhibit a rapid exponential decay in its impulse response weights. It is therefore inappropriate to model the series as a pure ARMA process. However, the series is clearly covariance stationary as the $d$ estimates lie below the 0.5 threshold of stationarity. The implications of the long-memory evidence in the ASE30 returns series can be seen in both the time and frequency domains. In the time domain, long memory is indicated by the fact that the returns series eventually exhibits strong positive dependence between distant observations. Such processes generate very slow, but eventual, decay in their impulse response weights. In the frequency domain, long memory is indicated by the fact that the spectral density becomes unbounded as the frequency approaches zero; the series has power at low frequencies. ${ }^{4}$

\section{Forecasting Greek Stock Index Returns}

The discovery of a fractional integration order in the Greek stock market suggests possibilities for constructing nonlinear econometric models for improved price forecasting performance, especially over longer forecasting horizons. The nonlinear model construction suggested is that of an ARFIMA process, which represents a flexible and parsimonious way to model both the short- and long-term dynamic properties of the series. Granger and

4 Through extensive Monte Carlo simulations, Cheung (1993) and Agiakloglou, Newbold, and Wohar (1993) found the spectral regression test to be biased toward finding long memory $(d>0)$ in the presence of infrequent shifts in the mean of the process and large AR parameters (0.7 and higher). We investigated the potential presence of these bias-inducing data features in the ASE30 returns series and found that neither a shift in mean nor strong short-term dynamics are responsible for detecting long memory in the Greek stock market. 
Joyeux (1980) have discussed the forecasting potential of such nonlinear models and Geweke and Porter-Hudak (1983) have confirmed this by showing that ARFIMA models provide more reliable out-of-sample forecasts than do traditional procedures. The possibility of speculative profits due to superior long-memory forecasts would cast serious doubt on the basic tenet of market efficiency: unpredictability of future returns. If the market is weakly efficient, stock prices should follow a random walk process. In this section the out-of-sample forecasting performance of an ARFIMA model is compared to that of benchmark linear models.

The following procedure is used to construct the long-memory models and forecasts. Given the spectral regression $d$ estimates, we approximate the short-run series dynamics by fitting an AR model to the fractionally differenced series using Box-Jenkins methods. An AR representation of generally low order is found to be an adequate description of short-term dependence in the data. The AR orders are selected on the basis of statistical significance of the coefficient estimates and $Q$ statistics for serial dependence (the AR order chosen in each case is given in subsequent tables). A question arises as to the asymptotic properties of the AR parameter estimates in the second stage. Conditioning on the $d$ estimate obtained in the first stage, Wright (1995) shows that the $\operatorname{AR}(p)$ fitted by the Yule-Walker procedure to the $d$-differenced series inherit the $T^{\delta}$-consistency of the semiparametric estimate of $d$.

The Greek stock returns series is forecast by casting the fitted fractional-AR model in infinite autoregressive form, truncating the infinite autoregression at the beginning of the sample, and applying Wold's chain rule. A similar procedure was followed by Ray (1993) to forecast IBM product revenues and Diebold and Lindner (1996) to forecast the real interest rate. The 
long-memory forecasts are compared to those obtained by estimating two standard linear models: a random walk (RW) model, as suggested by the market efficiency hypothesis in its weak form, and an autoregressive (AR) model fit to the ASE30 returns series according to the Akaike information criterion (AIC). The maximum autoregressive order allowed is 48, corresponding to a one-year period. The maximum value for the AIC function is obtained from an AR model of order 9. The maximum AR coefficient value is 0.144 with the sum of all AR coefficients being 0.368 .

The period from $10 / 18 / 1989$ to $12 / 27 / 1990$ has been reserved for outof-sample forecasting. The out-of-sample forecasting horizons considered are 1-week, 2-week, 3-week, 1-, 2-, 3-, 4-, 5-, 6-, 7-, 8-, 9-, 10-, 11-, and 12-month forecasting horizons. These forecasts are truly ex ante, or dynamic, as they are generated recursively conditioning only on information available at the time the forecast is being made. The criteria for forecasting performance are measures of root mean square error (RMSE) and mean absolute deviation (MAD).

In generating the out-of-sample forecasts, the model parameters are not reestimated each time; instead the in-sample estimates are repeatedly applied. A question arises as to whether the fractional differencing parameter remains stable over the out-of-sample period. To address this issue, we reestimate the fractional differencing parameter over the initial sample of 457 observations and then on subsequent samples generated by adding four observations until the total sample is exhausted. Figure 3 graphs the $d$ estimates for the various subsamples. With the exception of the $d$ estimates corresponding to a sample size of spectral regression of $v=T^{0.5}$, these estimates do not fluctuate noticeably, suggesting stability. Most of them lie in the range between 0.20 and 0.30 . The evidence strongly suggests that the $d$ estimates obtained from 
the various sizes of the spectral regression (except those for $v=T^{0.5}$ ) converge as the sample size increases. Therefore, basing the long-memory forecasts on the fractional differencing parameters estimated from the initial sample is not expected to negatively affect the out-of-sample forecasting performance.

Table 3 reports the ex-ante forecasting performance of the competing modeling strategies for the ASE30 returns series. Both fractional models and the AR model significantly outperform the random-walk forecasts over all forecasting horizons, suggesting market inefficiency. These improvements in forecasting accuracy increase monotonically with the length of forecasting horizon and hold true for both RMSE and MAD metrics. The superior performance of the long-memory fits over the RW fits holds true across the various estimates of $d$, suggesting robustness.

To provide a clearer picture of the relative forecasting performance of the alternative modeling strategies, Table 4 reports ratios of the forecasting criteria values (RMSE and MAD) attained by the various models. To conserve space, only the fractional model with the highest $d$ estimate is presented. ${ }^{5}$ The percentage reductions in forecasting accuracy obtained by the fractional and AR models over the RW model become dramatic as the forecasting horizon increases. As can be seen from both Tables 3 and 4, the AR forecasts compare favorably to the fractional-model forecasts. The AR forecasts have a slight edge up to a 28-week (7-month) forecasting horizon but they become inferior at longer horizons. The longer the forecasting horizon, the greater the forecasting improvement of the fractional model over that of the AR model.

5 Similar results (available on request) are obtained for the fractional models with alternative $d$ estimates. 
The forecasting performance of the long-memory model, as compared to that of the AR model, is consistent with theory. As the effects of the shortmemory (AR) parameters dominate over short horizons, the forecasting performance of the long-memory and linear models is rather similar in the short run. In the long run, however, the dynamic effects of the short-memory parameters are dominated by the fractional differencing parameter $d$, which captures the long-term correlation structure of the series, thus resulting in superior long-memory forecasts. In addition, the fractional model is a more flexible and parsimonious way of modeling both short-term and long-term properties of the ASE30 stock returns series. This evidence accentuates the usefulness of long-memory models as forecast generating mechanisms for Greek stock market returns, and casts doubt on the hypothesis of the weak form of market efficiency for longer horizons. It also strongly contrasts with the absence of long memory in major stock markets, providing evidence that emerging markets may have quite different characteristics.

\section{Conclusions}

Using the spectral regression method, we find significant evidence of fractional dynamics with long-memory features in the stock returns series of an emerging capital market, the Athens Stock Exchange in Greece. Price movements in the Greek stock market appear to be influenced by realizations from both the recent past and the remote past. The out-of-sample longmemory forecasts resulted in significant improvements in forecasting accuracy (especially over longer horizons) compared to random-walk forecasts. Long-memory forecasts also dominate autoregressive forecasts for horizons exceeding six months. This evidence contradicts the martingale 
model, which states that, conditioning on historical returns, future returns are unpredictable. The practical usefulness of developing long-memory models for the Greek stock market is therefore established.

The long-memory evidence obtained for the Greek stock market is in sharp contrast to that obtained for major capital markets. This suggests the possibility of differential long-term stochastic behavior between major and emerging capital markets, and invites examination of the long-memory properties of other emerging capital markets. Investment strategies involving multinational equities portfolios should be based on a complete characterization of stock returns in emerging capital markets. Our findings suggest that long-memory dynamics may prove to be an important element of that characterization. 


\section{References}

Agiakloglou, C., P. Newbold, and M. Wohar, 1993, Bias in an estimator of the fractional difference parameter, Journal of Time Series Analysis 14, 235246.

Barkoulas, J. T. and N. Travlos, 1996, Chaos in an emerging capital market? The case of the Athens stock exchange, Applied Financial Economics forthcoming.

Cheung, Y. W., 1993, Tests for fractional integration: A Monte Carlo investigation, Journal of Time Series Analysis 14, 331-345.

Cheung, Y. and K. Lai, 1995, A search for long memory in international stock market returns, Journal of International Money and Finance 14, 597-615.

Crato, N., 1994, Some international evidence regarding the stochastic behavior of stock returns, Applied Financial Economics 4, 33-39.

Diebold, F. X. and P. Lindner, 1996, Fractional integration and interval prediction, Economics Letters 50, 305-313.

Engle, R., 1982, Autoregressive conditional heteroscedasticity with estimates of the variance of U.K. inflation, Econometrica 50, 987-1008.

Geweke, J. and S. Porter-Hudak, 1983, The estimation and application of long memory time series models, Journal of Time Series Analysis 4, 221-238.

Granger, C. W. J. and R. Joyeux, 1980, An introduction to long-memory time series models and fractional differencing, Journal of Time Series Analysis 1, 15-39.

Greene, M. T. and B. D. Fielitz, 1977, Long-term dependence in common stock returns, Journal of Financial Economics 5, 339-349.

Hassler, U., 1993, Regression of spectral estimators with fractionally integrated time series, Journal of Time Series Analysis 14, 369-380. 
Hosking, J. R. M., 1981, Fractional differencing, Biometrika 68, 165-176.

Koutmos, G., Negakis, C. and P. Theodossiou, 1993, Stochastic behaviour of the Athens stock exchange, Applied Financial Economics 3, 119-126.

Lo, A. W., 1991, Long-term memory in stock market prices, Econometrica 59, 1279-1313.

Mandelbrot, B. B., 1971, When can price be arbitraged efficiently? A limit to the validity of the random walk and martingale models, Review of Economics and Statistics 53, 225-236.

Panas, E., 1990, The Behavior of the Athens stock prices, Applied Economics $22,1715-1727$.

Papaioannou, G. J., 1982, Thinness and short-run price dependence in the Athens stock exchange, Greek Economic Review, 315-333.

Papaioannou, G. J., 1984, Informational efficiency tests in the Athens stock market, in G. A. Hawawini and P. A. Michel, eds., European Equity Markets: Risk, Return, and Efficiency (Garland Publishing, Inc., New York) 367-381.

Ray, B., 1993, Long range forecasting of IBM product revenues using a seasonal fractionally differenced ARMA model, International Journal of Forecasting 9, 255-269.

Robinson, P., 1990, Time series with strong dependence, Advances in Econometrics, 6th World Congress (Cambridge University Press, Cambridge).

Theodossiou, P., Koutmos, G. and C. Negakis, 1993, The intertemporal relation between the U.S. and Greek stock markets: A conditional tale analysis, International Journal of Finance 6, 492-508.

Travlos, N., 1992, Athens stock exchange: Creation of a stock market data bank and risk-returns characteristics for the period 1981-1990, University of 
Piraeus, unpublished monograph.

Wright, J. H., 1995, Stochastic orders of magnitude associated with two-stage estimators of fractional ARIMA systems, Journal of Time Series Analysis 16, 119-125.

Yajima, Y., 1985, Estimation of long memory time series models, Australian Journal of Statistics 27, 303-320. 
Table 1: Summary Statistics of ASE30 Weekly Returns Series (01/07/1981-10/11/1989)

\begin{tabular}{ll}
\hline \hline Statistic & ASE30 \\
\hline Mean & $0.00723^{* * *}$ \\
Median & 0.00338 \\
Standard Deviation & 0.04689 \\
Skewness & $0.66093^{* * *}$ \\
Kurtosis & $7.12527^{* * *}$ \\
Minimum & -0.24683 \\
Maximum & 0.26733 \\
\hline \hline
\end{tabular}

*** indicates statistical significance at the 1 per cent level. 
Table 2: Estimates of the Fractional-Differencing Parameter $d$ for Weekly ASE30 Returns Series

\begin{tabular}{ccccc}
\hline \hline$d(0.50)$ & $d(0.525)$ & $d(0.55)$ & $d(0.575)$ & $d(0.60)$ \\
\hline $\begin{array}{c}0.219 \\
(1.252)\end{array}$ & $\begin{array}{c}0.305 \\
(1.896)^{*} \text {, 拄 }\end{array}$ & $\begin{array}{c}0.266 \\
(1.860)^{*} \text {, 拄 }\end{array}$ & $\begin{array}{c}0.271 \\
(2.053)^{* *} \text {, 拄 }\end{array}$ & $\begin{array}{c}0.297 \\
(2.492)^{* *} \text {, 圷圷 }\end{array}$ \\
\hline \hline
\end{tabular}

Notes: The sample corresponds to the in-sample period $01 / 07 / 1981-10 / 11 / 1989$. $d(0.50)$, $d(0.525), d(0.55), d(0.575)$, and $d(0.60)$ give the $d$ estimates corresponding to the spectral regression of sample size $v=T^{0.50}, v=T^{0.525}, v=T^{0.55}, v=T^{0.575}$, and $v=T^{0.60}$. The $t$-statistics are given in parentheses and are constructed imposing the known theoretical error variance of $\pi^{2} / 6$. The superscripts $* * * * * *$ indicate statistical significance for the null hypothesis $d=0$ against the alternative $d \neq 0$ at the 1,5 , and 10 per cent levels, respectively. The superscripts 拉, 拉 $\ddagger$ indicate statistical significance for the null hypothesis $d=0$ against the one-sided alternative $d>0$ at the 1,5 , and 10 per cent levels, respectively. 
Table 3: Out-of-sample Forecasting Performance of Alternative Modeling Strategies for the Weekly ASE30 Returns Series

\begin{tabular}{|c|c|c|c|c|c|}
\hline \multirow{3}{*}{$\begin{array}{l}\text { Forecasting } \\
\text { Horizon } \\
\text { (K-steps Ahead) }\end{array}$} & \multicolumn{3}{|c|}{ Forecasting Model } & \multirow{3}{*}{$\mathrm{AR}(9)$} & \multirow{3}{*}{$\overline{\mathrm{RW}}$} \\
\hline & \multicolumn{3}{|c|}{ Fractional Model } & & \\
\hline & $d=0.219, \operatorname{AR}(2)$ & $d=0.305, \operatorname{AR}(2)$ & $d=0.266, \mathrm{AR}(2)$ & & \\
\hline \multirow[b]{2}{*}{1} & 0.0779 & 0.0778 & 0.0778 & 0.0756 & 0.0799 \\
\hline & 0.0645 & 0.0644 & 0.0644 & 0.0613 & 0.0664 \\
\hline \multirow[b]{2}{*}{2} & 0.1098 & 0.1092 & 0.1094 & 0.1076 & 0.1159 \\
\hline & 0.0897 & 0.0897 & 0.0896 & 0.0893 & 0.0937 \\
\hline \multirow{2}{*}{3} & 0.1409 & 0.1399 & 0.1402 & 0.1371 & 0.1525 \\
\hline & 0.1189 & 0.1154 & 0.1171 & 0.1172 & 0.1254 \\
\hline \multirow[b]{2}{*}{4} & 0.1750 & 0.1739 & 0.1742 & 0.1699 & 0.1904 \\
\hline & 0.1501 & 0.1458 & 0.1477 & 0.1472 & 0.1594 \\
\hline \multirow{2}{*}{8} & 0.2981 & 0.2942 & 0.2958 & 0.2830 & 0.3295 \\
\hline & 0.2621 & 0.2571 & 0.2596 & 0.2510 & 0.2831 \\
\hline \multirow{2}{*}{12} & 0.4389 & 0.4399 & 0.4393 & 0.4184 & 0.4740 \\
\hline & 0.3831 & 0.3777 & 0.3805 & 0.3674 & 0.4154 \\
\hline \multirow{2}{*}{16} & 0.5681 & 0.5781 & 0.5731 & 0.5468 & 0.6061 \\
\hline & 0.4940 & 0.4992 & 0.4968 & 0.4780 & 0.5394 \\
\hline \multirow{2}{*}{20} & 0.6751 & 0.6967 & 0.6861 & 0.6562 & 0.7240 \\
\hline & 0.5906 & 0.6071 & 0.5983 & 0.5787 & 0.6431 \\
\hline \multirow{2}{*}{24} & 0.7351 & 0.7611 & 0.7478 & 0.7212 & 0.8216 \\
\hline & 0.6603 & 0.6821 & 0.6701 & 0.6486 & 0.7261 \\
\hline \multirow{2}{*}{28} & 0.7457 & 0.7529 & 0.7481 & 0.7463 & 0.9130 \\
\hline & 0.6749 & 0.6783 & 0.6755 & 0.6694 & 0.7866 \\
\hline \multirow{2}{*}{32} & 0.7588 & 0.7531 & 0.7541 & 0.7686 & 0.9875 \\
\hline & 0.6600 & 0.6514 & 0.6539 & 0.6613 & 0.8729 \\
\hline \multirow[b]{2}{*}{36} & 0.7605 & 0.7379 & 0.7471 & 0.7768 & 1.0473 \\
\hline & 0.6554 & 0.6402 & 0.6468 & 0.6615 & 0.9660 \\
\hline \multirow{2}{*}{40} & 0.7032 & 0.6727 & 0.6856 & 0.7216 & 1.0332 \\
\hline & 0.6029 & 0.5667 & 0.5827 & 0.6172 & 0.9783 \\
\hline \multirow{2}{*}{44} & 0.6312 & 0.5920 & 0.6091 & 0.6500 & 1.0051 \\
\hline & 0.5824 & 0.5301 & 0.5543 & 0.5991 & 0.9769 \\
\hline \multirow{2}{*}{48} & 0.5499 & 0.5066 & 0.5257 & 0.5683 & 0.9613 \\
\hline & 0.5387 & 0.4910 & 0.5129 & 0.5560 & 0.9512 \\
\hline
\end{tabular}

Notes: The out-of-sample period is from $10 / 18 / 1989$ to 12/27/90. The first entry of each cell is the root mean squared error (RMSE), while the second is the mean absolute deviation (MAD). $\mathrm{AR}(\mathrm{k})$ stands for an autoregression model of order k. RW stands for random walk. The longmemory model consists of the fractional differencing parameter $d$ and the order of the AR polynomial. The coefficient estimates and associated test statistics for the various AR models are available upon request. 
Table 4: Relative Out-of-sample Forecasting Performance of Alternative Modeling Strategies for the Weekly ASE30 Returns Series

\begin{tabular}{|c|c|c|c|}
\hline $\begin{array}{l}\text { Forecasting Horizon } \\
\text { (K-steps Ahead) }\end{array}$ & $\begin{array}{c}\text { Fractional } \\
\text { Model/RW }\end{array}$ & $\mathrm{AR} / \mathrm{RW}$ & $\begin{array}{r}\text { Fractional } \\
\text { Model/AR }\end{array}$ \\
\hline 1 & $\begin{array}{l}0.9737 \\
0.9699\end{array}$ & $\begin{array}{l}0.9462 \\
0.9232\end{array}$ & $\begin{array}{l}1.0291 \\
1.0506\end{array}$ \\
\hline 2 & $\begin{array}{l}0.9422 \\
0.9573\end{array}$ & $\begin{array}{l}0.9284 \\
0.9530\end{array}$ & $\begin{array}{l}1.0149 \\
1.0045\end{array}$ \\
\hline 3 & $\begin{array}{l}0.9174 \\
0.9203\end{array}$ & $\begin{array}{l}0.8990 \\
0.9346\end{array}$ & $\begin{array}{l}1.0204 \\
0.9846\end{array}$ \\
\hline 4 & $\begin{array}{l}0.9133 \\
0.9147\end{array}$ & $\begin{array}{l}0.8923 \\
0.9235\end{array}$ & $\begin{array}{l}1.0235 \\
0.9905\end{array}$ \\
\hline 8 & $\begin{array}{l}0.8929 \\
0.9082\end{array}$ & $\begin{array}{l}0.8589 \\
0.8866\end{array}$ & $\begin{array}{l}1.0396 \\
1.0243\end{array}$ \\
\hline 12 & $\begin{array}{l}0.9281 \\
0.9092\end{array}$ & $\begin{array}{l}0.8827 \\
0.8844\end{array}$ & $\begin{array}{l}1.0514 \\
1.0280\end{array}$ \\
\hline 16 & $\begin{array}{l}0.9538 \\
0.9255\end{array}$ & $\begin{array}{l}0.9022 \\
0.8862\end{array}$ & $\begin{array}{l}1.0572 \\
1.0444\end{array}$ \\
\hline 20 & $\begin{array}{l}0.9623 \\
0.9440\end{array}$ & $\begin{array}{l}0.9064 \\
0.8999\end{array}$ & $\begin{array}{l}1.0617 \\
1.0491\end{array}$ \\
\hline 24 & $\begin{array}{l}0.9264 \\
0.9394\end{array}$ & $\begin{array}{l}0.8778 \\
0.8933\end{array}$ & $\begin{array}{l}1.0553 \\
1.0516\end{array}$ \\
\hline 28 & $\begin{array}{l}0.8246 \\
0.8623\end{array}$ & $\begin{array}{l}0.8174 \\
0.8510\end{array}$ & $\begin{array}{l}1.0088 \\
1.0133\end{array}$ \\
\hline 32 & $\begin{array}{l}0.7626 \\
0.7462\end{array}$ & $\begin{array}{l}0.7783 \\
0.7576\end{array}$ & $\begin{array}{l}0.9798 \\
0.9850\end{array}$ \\
\hline 36 & $\begin{array}{l}0.7046 \\
0.6627\end{array}$ & $\begin{array}{l}0.7417 \\
0.6848\end{array}$ & $\begin{array}{l}0.9499 \\
0.9678\end{array}$ \\
\hline 40 & $\begin{array}{l}0.6511 \\
0.5793\end{array}$ & $\begin{array}{l}0.6984 \\
0.6309\end{array}$ & $\begin{array}{l}0.9322 \\
0.9182\end{array}$ \\
\hline 44 & $\begin{array}{l}0.5890 \\
0.5426\end{array}$ & $\begin{array}{l}0.6467 \\
0.6133\end{array}$ & $\begin{array}{l}0.9108 \\
0.8848\end{array}$ \\
\hline 48 & $\begin{array}{l}0.5270 \\
0.5162\end{array}$ & $\begin{array}{l}0.5912 \\
0.5845\end{array}$ & $\begin{array}{l}0.8914 \\
0.8831\end{array}$ \\
\hline
\end{tabular}

\footnotetext{
Notes: The long-memory model for the ASE30 returns series is that corresponding to the highest $d$ estimate (0.305). Similar results are obtained for the other long-memory model specifications reported in Table 3. The first (second) entry in each cell is the ratio of the RMSE (MAD) values achieved from alternative modeling strategies. AR stands for an autoregressive model of order 9. RW stands for random walk. Fractional model/RW is the ratio of the forecasting criteria values (RMSE and MAD) obtained from the fractional model to those obtained from the RW model. AR/RW and fractional model/AR are similarly defined. See Table 3 for additional explanation of the table.
} 
Figure 1: ASE30 Weekly Returns Series (01/07/1981-12/27/1990)

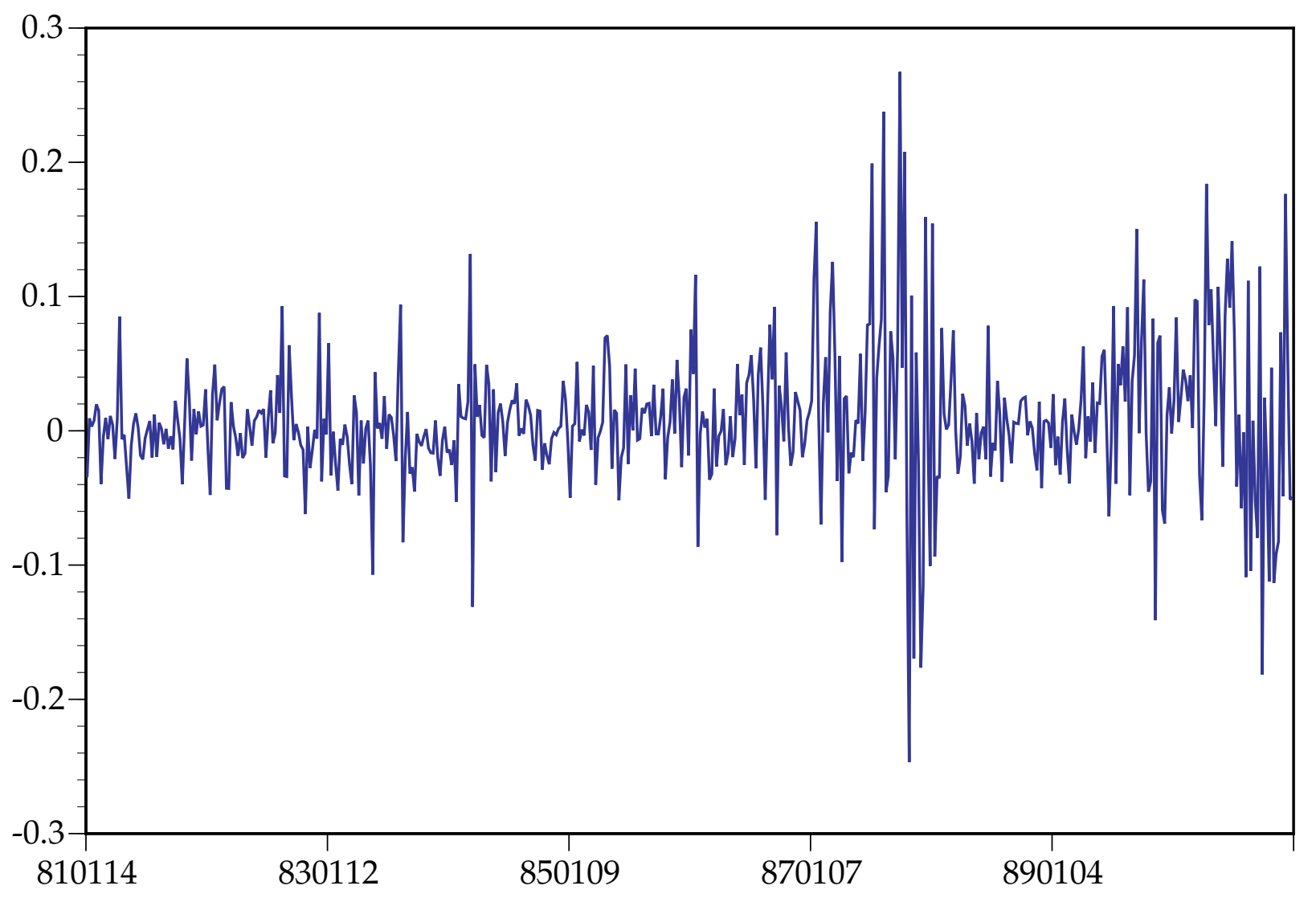


Figure 2: Yearly Returns on the ASE30 Stock Index

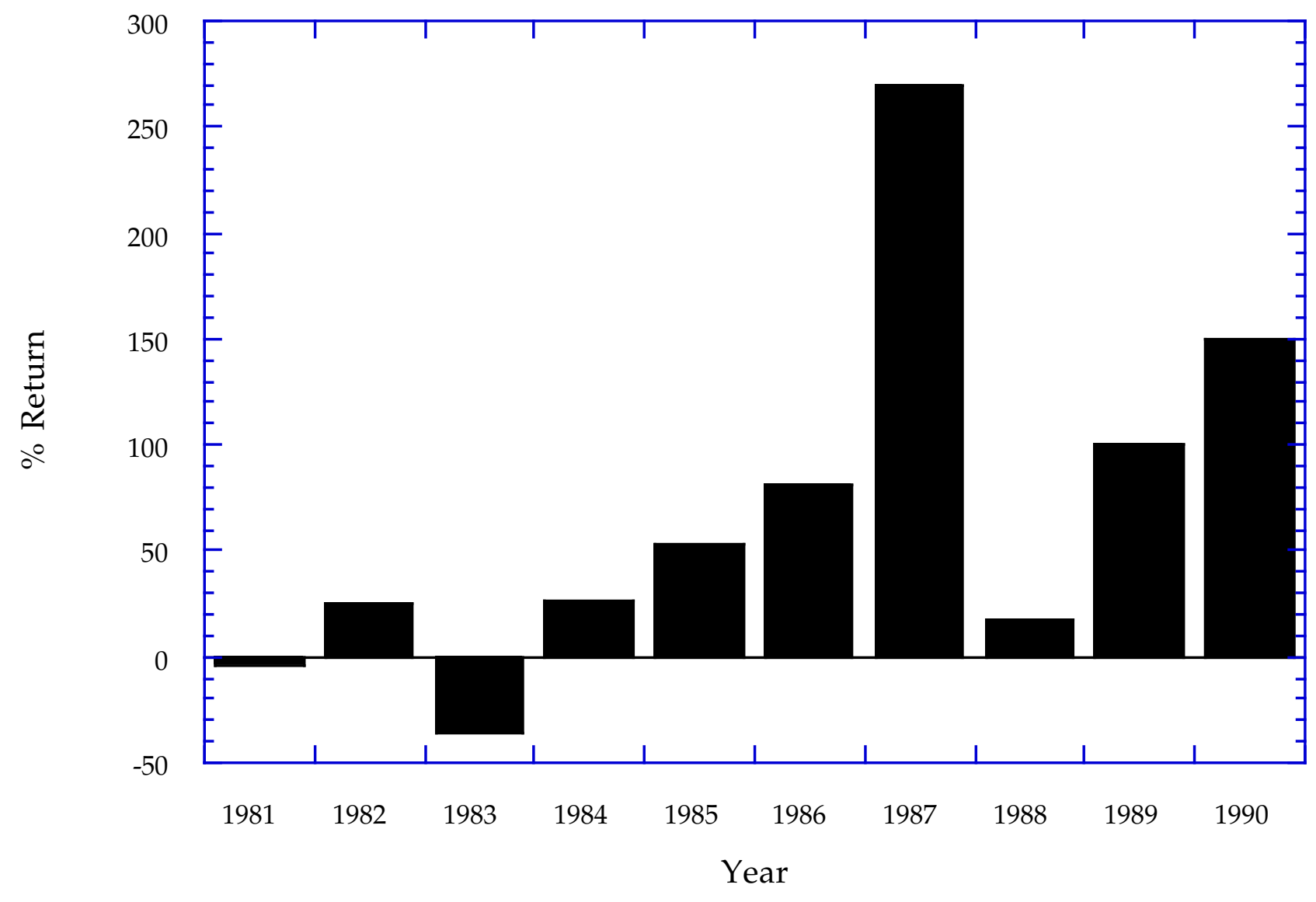


Figure 3: Fractional Differencing Estimates over Subsamples of the ASE30 Weekly Returns Series

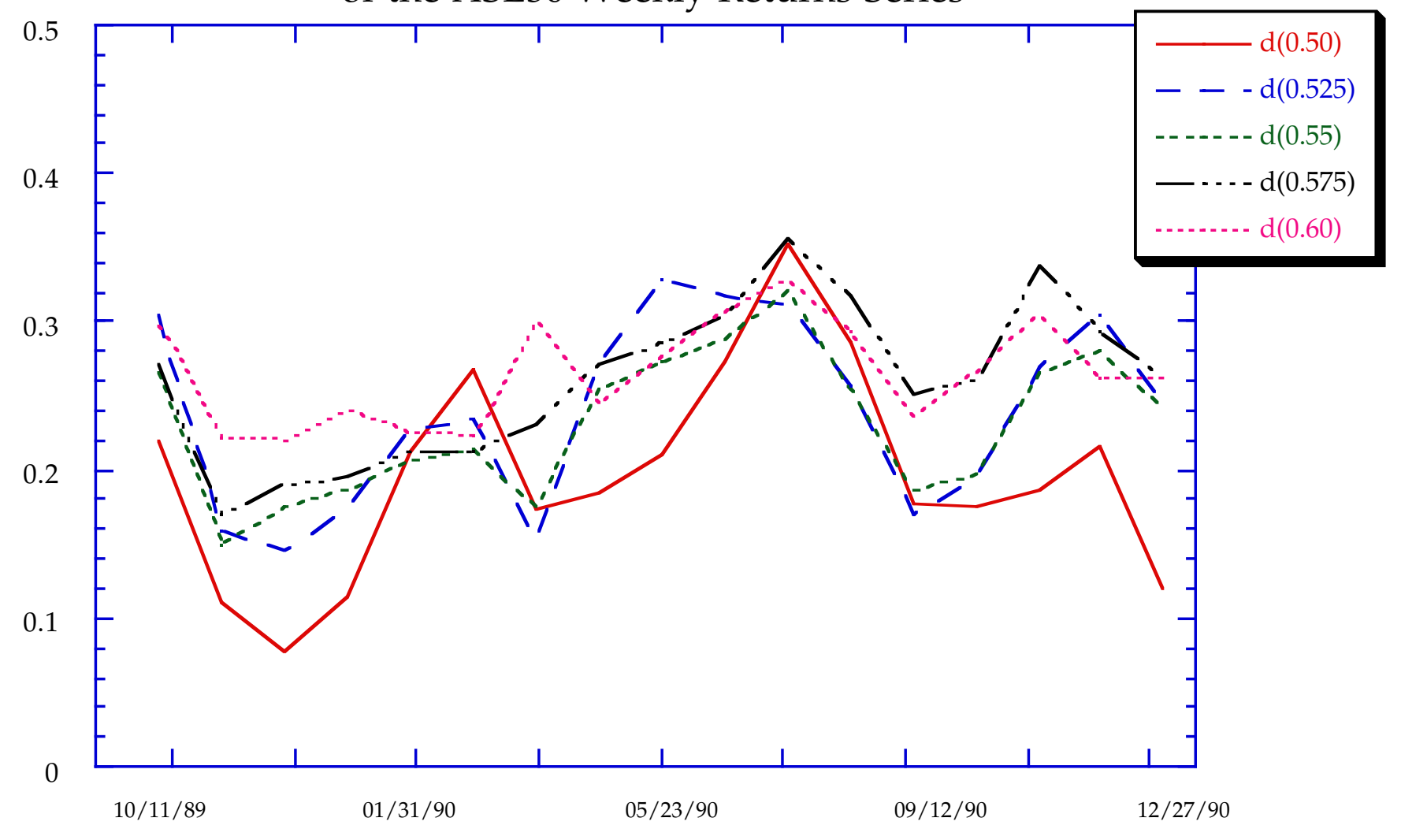

